\title{
BMJ Open COVID-19 in Ethiopia: a geospatial analysis of vulnerability to infection, case severity and death
}

Kefyalew Addis Alene, ${ }^{1,2,3}$ Yalemzewod Assefa Gelaw, ${ }^{3,4}$

Dagnachew Muluye Fetene, ${ }^{5}$ Digsu N. Koye, ${ }^{6}$ Yohannes Adama Melaku (1) ,7 Hailay Gesesew (1) , 7,8 Mulugeta Molla Birhanu, ${ }^{9,10}$ Akilew Awoke Adane (D) ,3,11 Muluken Dessalegn Muluneh, ${ }^{12,13}$ Berihun Assefa Dachew (D) ,,3

Solomon Abrha, ${ }^{14,15}$ Atsede Aregay, ${ }^{16,17}$ Asnakew Achaw Ayele, ${ }^{18,19}$

Woldesellassie M Bezabhe (D) ,20 Kidane Tadesse Gebremariam, ${ }^{8,21,22}$

Tesfaye Gebremedhin, ${ }^{14}$ Amanuel Tesfay Gebremedhin, ${ }^{1,2}$

Lemlem Gebremichael, ${ }^{15,23}$ Ayele Bali Geleto, ${ }^{24,25}$ Habtamu Tilahun Kassahun, ${ }^{26}$ Getiye Dejenu Kibret, ${ }^{27,28}$ Cheru Tesema Leshargie, ${ }^{27,28}$ Alemayehu Mekonnen, ${ }^{29,30}$ Alemnesh H. Mirkuzie, ${ }^{31,32}$ Hassen Mohammed, ${ }^{33,34}$ Henok Getachew Tegegn (1D , ${ }^{19,35}$ Azeb Gebresilassie Tesema, ${ }^{8,36}$ Fisaha Haile Tesfay (i) , 8,37 Befikadu Legesse Wubishet, ${ }^{25}$ Yohannes Kinfu (iD) ${ }^{14,38}$

To cite: Alene KA, Gelaw YA, Fetene DM, et al. COVID-19 in Ethiopia: a geospatial analysis of vulnerability to infection, case severity and death. BMJ Open 2021;11:e044606. doi:10.1136/ bmjopen-2020-044606

- Prepublication history and additional materials for this paper is available online. To view these files, please visit the journal online (http://dx.doi. org/10.1136/bmjopen-2020044606).

YAG and YK contributed equally.

Received 09 September 2020 Revised 27 January 2021 Accepted 27 January 2021

\section{SLinked}

http://dx.doi.org/10.1136/ bmjopen-2020-044618

Check for updates

(C) Author(s) (or their employer(s)) 2021. Re-use permitted under CC BY-NC. No commercial re-use. See rights and permissions. Published by BMJ.

For numbered affiliations see end of article.

Correspondence to Dr Kefyalew Addis Alene; kefyalew.alene@curtin.edu.au

\section{ABSTRACT}

Background COVID-19 has caused a global public health crisis affecting most countries, including Ethiopia, in various ways. This study maps the vulnerability to infection, case severity and likelihood of death from COVID-19 in Ethiopia.

Methods Thirty-eight potential indicators of vulnerability to COVID-19 infection, case severity and likelihood of death, identified based on a literature review and the availability of nationally representative data at a low geographic scale, were assembled from multiple sources for geospatial analysis. Geospatial analysis techniques were applied to produce maps showing the vulnerability to infection, case severity and likelihood of death in Ethiopia at a spatial resolution of $1 \mathrm{~km} \times 1 \mathrm{~km}$.

Results This study showed that vulnerability to COVID-19 infection is likely to be high across most parts of Ethiopia, particularly in the Somali, Afar, Amhara, Oromia and Tigray regions. The number of severe cases of COVID-19 infection requiring hospitalisation and intensive care unit admission is likely to be high across Amhara, most parts of Oromia and some parts of the Southern Nations, Nationalities and Peoples' Region. The risk of COVID-19-related death is high in the country's border regions, where public health preparedness for responding to COVID-19 is limited. Conclusion This study revealed geographical differences in vulnerability to infection, case severity and likelihood of death from COVID-19 in Ethiopia. The study offers maps that can guide the targeted interventions necessary to contain the spread of COVID-19 in Ethiopia.

\section{INTRODUCTION}

COVID-19 has become one of the most serious global public health crises in modern times. ${ }^{1}$ The disease was declared a pandemic

\section{Strengths and limitations of this study}

- This is the first study that maps vulnerability to COVID-19 infection, severe cases and associated death in Ethiopia at a high level of resolution across the entire territory of Ethiopia.

- This is also the first study that has attempted to present the degree of service preparedness for COVID-19 across the country.

- The study incorporated a wide range of indicators from multiple sources and applied rigorous geospatial techniques to provide the best possible prediction maps.

- However, some important indicators such as psychosocial and clinical factors were not captured in our modelling due to the lack of geocoded data.

on 11 March 2020 and has currently affected more than 216 countries and territories. ${ }^{2}$ As of 3 August 2020, there were more than 17.6 million confirmed COVID-19 cases and over 680000 associated deaths around the globe. ${ }^{3}$ The highest numbers of cases and deaths have been reported from the USA, Brazil, India and some European countries, such as Russia, the UK, Italy and Spain. ${ }^{3}$ African countries, including Ethiopia, have reported a low number of COVID-19, although the number of cases and deaths are currently on the rise. ${ }^{4}$ In Ethiopia, the first case of COVID-19 was reported on 13 March 2020 in Addis Ababa, but at the time of this study almost all regions of the country were affected by COVID-19 at different 
magnitudes. ${ }^{5}$ However, the number of cases in Ethiopia is still very low due to limited testing capacity and delays in reporting confirmed cases.

Multiple factors, such as sociodemographic, connectivity, behavioural, climatic and comorbidity factors, are strong predictors of the differences in transmission, hospitalisation and mortality rates among and within countries. ${ }^{67}$ Studies conducted in Africa have provided limited information on the vulnerability of different areas to COVID-19 infection. ${ }^{4}{ }^{8}$ These studies have been conducted at the country level using a limited number of indicators. ${ }^{4}$ Mapping the risks of COVID-19 (infection, case severity, service preparedness and death) at the lowest administrative unit, such as the district, is important in many ways. First, the generated evidence can help the government and community better prepare and respond to the health-related and non-health-related impacts of COVID-19 according to their contextual circumstances. Second, it can help the relevant bodies determine effective and efficient resource-mobilisation efforts, such as providing training for healthcare workers, supplying hospitals with necessary equipment, prioritising testing practices and distributing hand sanitiser and protective facemasks. Third, the information can be used as a guide for designing targeted travel restrictions or applying full or partial lockdowns as needed. Fourth, the evidence can stimulate further study on COVID-19 in the country.

Given Ethiopia's large population size, variation in resources and vast geographic size, the risk of COVID-19 infection, case severity and likelihood of death are likely to differ across regions, zones and districts, suggesting that local and context-specific interventions be implemented. Therefore, this study aimed to map the vulnerability to infection, case severity and likelihood of death from COVID-19 in Ethiopia using rigorous state-of-the-art geospatial techniques.

\section{METHODS}

\section{Study area}

This study focused on Ethiopia, the second-most populous country in Africa, with an estimated population size of more than 115 million. ${ }^{9}$ Ethiopia has a total area of approximately 1.1 million square kilometres, making it the 10th largest country in Africa and the 27th largest in the world. The country has a tiered administrative system consisting of regional states (first level), zones (second level), woredas or districts (third level), and kebeles or neighbourhoods (fourth level).$^{10}$ There are nine administrative regional states in Ethiopia, including Tigray, Afar, Amhara, Oromia, Somali, Benishangul-Gumuz, Harari, Gambella, and the Southern Nations, Nationalities, and Peoples' Region (SNNPR), and two administrative cities (Addis Ababa and Diredawa). Four of these regional states (namely, Afar, Somali, BenishangulGumuz and Gambella) are relatively less developed, and categorised as developing regional states. They lag behind the rest of the country in all indicators related to human development and disease prevention and control programmes. The administrative units of Ethiopia (shapefiles) were obtained from the Database for Global Administrative Areas. ${ }^{11}$

\section{Data sources and variable selection}

The data for this study were assembled from multiple sources (table 1). Potential indicators were selected based on evidence of association with COVID-19 infection, case severity and death based on a literature review and the availability of country-wide representative data at a district geographic scale or lower (figure 1). Table 2 presents the evidence for the association between indicators and COVID-19, as well as the rationale for selecting these indicators for the study.

The following area-level demographic and socioeconomic indicators were used as indicators of COVID-19 infection and case severity: the average number of persons per household, the proportion of the population aged $\geq 65$ years, the proportion of males and the number of households in the lowest wealth quintile. All of these socioeconomic and demographic indicators were obtained from the latest Ethiopia Demographic and Health Survey (EDHS).$^{12}$ A map showing the distribution of EDHS datapoints are available as online supplemental figure 1. Population density, estimated as the number of people per grid, was obtained from WorldPop. ${ }^{13}$

Connectivity indicators, which measure the populationlevel vulnerability to infection, were also captured using distance and time-bounded markers. Specifically, average travel time (measured in minutes) to the nearest city and proximity to international borders (measured in kilometres) were included to measure each area's level of susceptibility to infection. Data on travel time to the nearest city, obtained from the University of Oxford's Malaria Atlas Project (MAP), were used to quantify the accessibility of an area to high-density urban centres at a resolution of $1 \mathrm{~km} \times 1 \mathrm{~km} .{ }^{14}$ Data on proximity to international borders were obtained from the EDHS spatial data repository and were used to measure ${ }^{15}$ the geodesic distance to the nearest international border in kilometres, indicating the risk of cross-border transmission and the spread of COVID-19. Infection rates and the spread of COVID-19 were also positively correlated with the per capita public transportation use rate. ${ }^{16}$ Thus, to determine the nearest cross-country road to each location on the map, we obtained and applied data for major roads from the World Bank. ${ }^{17}$

It is evident that inadequate knowledge about COVID-19 and a lack of awareness of prevention measures exacerbate community transmission of the disease. ${ }^{18}$ Therefore, we extracted data on adult literacy rate, access to media (such as radio, television and mobile phone messages) and knowledge about other infectious diseases (eg, HIV) from the EDHS as proxies for knowledge of COVID-19 prevention measures in each area of the country. ${ }^{12}$ According to the WHO, maintaining good hand hygiene through regular washing with soap and water is one of the most effective preventative 
Table 1 Data sources and definitions of indicators for the vulnerability of COVID-19 in Ethiopia

\begin{tabular}{|c|c|c|c|}
\hline Indicators & Data sources & Spatial resolution & Definitions \\
\hline \multicolumn{4}{|c|}{ Demographic indicators } \\
\hline Male sex & EDHS 2016 & Latitude and longitude point & $\begin{array}{l}\text { Total number of male populations divided by the total number } \\
\text { people participated in the survey }\end{array}$ \\
\hline Older age & EDHS 2016 & Latitude and longitude point & $\begin{array}{l}\text { Total number of people with age } \geq 65 \text { years divided by the total } \\
\text { number of people participated in the survey }\end{array}$ \\
\hline
\end{tabular}

Socioeconomic indicators

$\begin{array}{llll}\text { Population density } & \text { WorldPop } & 1 \mathrm{~km} \times 1 \mathrm{~km} & \text { Number of people per square kilometre (grid) } \\ \text { Number of household } & \text { EDHS 2016 } & \text { Latitude and longitude point } & \text { Average number of people living in a house }\end{array}$

members

Low wealth index EDHS $2016 \quad$ Latitude and longitude point Number of people with low wealth index (poorer and poorest) divided by the total number of people participated in the survey

Connectivity indicators

\begin{tabular}{|c|c|c|c|}
\hline Travel times to cities & MAP & $1 \mathrm{~km} \times 1 \mathrm{~km}$ & $\begin{array}{l}\text { Travel time in minutes to the nearest city with a population of } \\
\text { more than } 50000\end{array}$ \\
\hline Proximity to national borders & $\begin{array}{l}\text { DHS Spatial } \\
\text { Repository }\end{array}$ & Latitude and longitude point & The geodesic distance to the nearest international borders \\
\hline Distance to major roads & World Bank & District & Distance in $\mathrm{km}$ to cross-country round \\
\hline \multicolumn{4}{|l|}{ Climatic indicators } \\
\hline Mean temperature & WorldClime & $1 \mathrm{~km} \times 1 \mathrm{~km}$ & Annual mean environmental air temperature $\left({ }^{\circ} \mathrm{C}\right)$ \\
\hline Mean precipitation & WorldClime & $1 \mathrm{~km} \times 1 \mathrm{~km}$ & Annual mean rainfall (mm) \\
\hline Wind speed & WorldClime & $1 \mathrm{~km} \times 1 \mathrm{~km}$ & Annual mean wind speed $\left(\mathrm{m} \mathrm{s}^{-1}\right)$ \\
\hline Solar radiation & WorldClime & $1 \mathrm{~km} \times 1 \mathrm{~km}$ & Annual mean solar radiation $\left(\mathrm{kJ} \mathrm{m}^{-2}\right.$ day $\left.^{-1}\right)$ \\
\hline Water vapour pressure & WorldClime & $1 \mathrm{~km} \times 1 \mathrm{~km}$ & $\begin{array}{l}\text { Annual mean water vapour pressure }(\mathrm{kPa}) \text {, equivalent to } \\
\text { absolute humidity }\end{array}$ \\
\hline
\end{tabular}

Behavioural indicators

\begin{tabular}{|c|c|c|c|}
\hline Khat chewing & EDHS 2016 & Latitude and longitude point & $\begin{array}{l}\text { Total number of people chewing khat in the last } 1 \text { month prior to } \\
\text { the survey divided by the total number of people participating in } \\
\text { the survey }\end{array}$ \\
\hline Alcohol drinking & EDHS 2016 & Latitude and longitude point & $\begin{array}{l}\text { Total number of people drinking alcohol in the month prior to } \\
\text { the survey divided by the total number of people participating in } \\
\text { the survey }\end{array}$ \\
\hline Cigarette smoking & EPHI STEPS & Latitude and longitude point & $\begin{array}{l}\text { Total number of people currently smoke cigarettes divided by } \\
\text { the total number of people participating in the survey }\end{array}$ \\
\hline Use solid fuel for cooking & EDHS 2016 & Latitude and longitude point & $\begin{array}{l}\text { Number of households used some type of solid fuel (wood, } \\
\text { dung, grass, crop) for cooking food divided by all households in } \\
\text { the survey }\end{array}$ \\
\hline
\end{tabular}

Disease prevention knowledge indicators

\begin{tabular}{|llll}
\hline Adult illiteracy rate & EDHS 2016 & Latitude and longitude point & $\begin{array}{l}\text { Total number of adults (aged 15 years and above) who had not } \\
\text { attended school or who cannot read and write divided by the } \\
\text { total number of adults participated in the survey }\end{array}$ \\
\hline Access to listen to the radio & EDHS 2016 & Latitude and longitude point & $\begin{array}{l}\text { Total number of people who had not access to listen to the } \\
\text { radio divided by total survey participants }\end{array}$ \\
\hline Access to watch TV & EDHS 2016 & Latitude and longitude point & $\begin{array}{l}\text { Total number of people have no access to watch television } \\
\text { divided by total survey participants }\end{array}$ \\
\hline Mobile phone ownership & EDHS 2016 & Latitude and longitude point & $\begin{array}{l}\text { Total number of people have no access to mobile phone divide } \\
\text { by the total number of survey participants }\end{array}$ \\
\hline Knowledge toward HIV & EDHS 2016 & Latitude and longitude point & $\begin{array}{l}\text { Number of people with poor knowledge towards HIV divided by } \\
\text { the total number of people participating in the survey }\end{array}$
\end{tabular}

Hand hygiene indicators 
Table 1 Continued

\begin{tabular}{|c|c|c|c|}
\hline Indicators & Data sources & Spatial resolution & Definitions \\
\hline Travel time to water sources & EDHS 2016 & Latitude and longitude point & $\begin{array}{l}\text { Mean travel time in minutes to obtain water source (ie, access } \\
\text { to a water source) }\end{array}$ \\
\hline $\begin{array}{l}\text { Soap or detergent availability } \\
\text { for handwashing }\end{array}$ & EDHS 2016 & Latitude and longitude point & $\begin{array}{l}\text { Number of households have no essential handwashing agents } \\
\text { (ie, soap, and detergent) divided by total household in the } \\
\text { survey }\end{array}$ \\
\hline
\end{tabular}

Comorbidities indicators

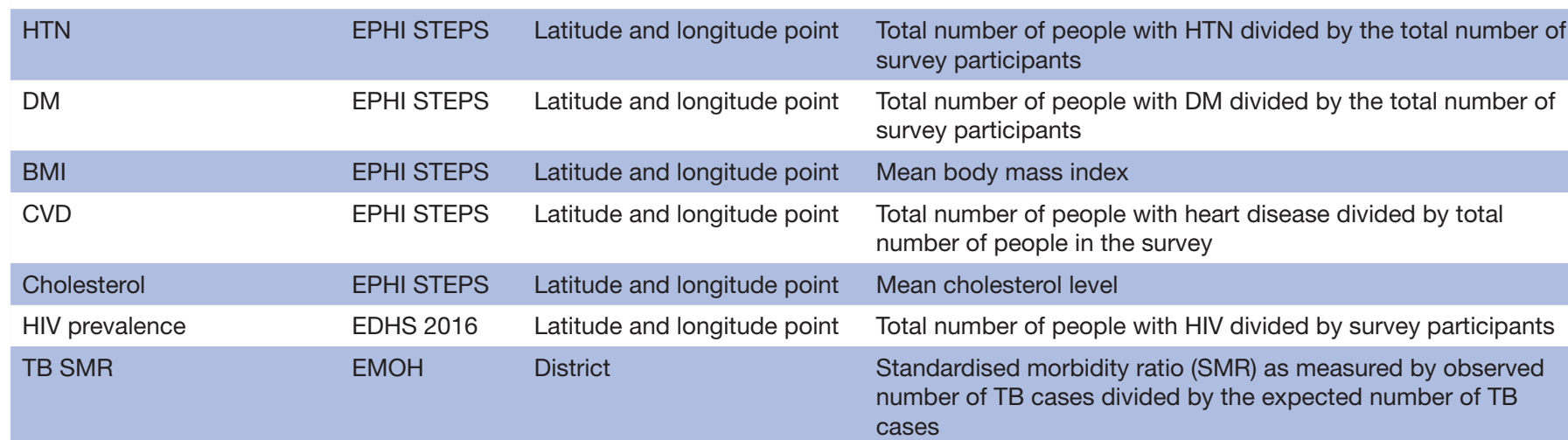

Service availability and readiness indicators

\begin{tabular}{|c|c|c|c|}
\hline Healthcare access problem & EDHS 2016 & Latitude and longitude point & $\begin{array}{l}\text { Difficulty of getting advice or treatment due to lack of money, or } \\
\text { distance to a health facility }\end{array}$ \\
\hline $\begin{array}{l}\text { General service readiness } \\
\text { and availability }\end{array}$ & EPHI SARA & Latitude and longitude point & $\begin{array}{l}\text { Availability of equipment and supplies (ie, basic amenities, } \\
\text { equipment, standard precautions, diagnostic capacity, essential } \\
\text { medicines) necessary to provide general health services }\end{array}$ \\
\hline ICU availability & EPHI SARA & Latitude and longitude point & Availability of Critical Care Services (ICU) in hospitals \\
\hline CRD readiness index & EPHI SARA & Latitude and longitude point & $\begin{array}{l}\text { Availability of specific services for chronic respiratory disease } \\
\text { (CRD) diagnosis, management and follow-up }\end{array}$ \\
\hline Diabetes readiness index & EPHI SARA & Latitude and longitude point & $\begin{array}{l}\text { Availability of specific service for diabetes diagnosis and } \\
\text { management and follow-up }\end{array}$ \\
\hline
\end{tabular}

EDHS, Ethiopia ddemographic and Health Survey; EMOH, Ethiopia Ministry of Health; EPHI, Ethiopia Public Health Institute; G-Econ, Geographically based Economic data; ICU, intensive care unit; MAP: SRTM, Malaria Atlas Project; Shuttle Radar Topography Mission; UN OCHA, United Nation Office for Coordination of Humanitarian Affairs; SARA, Service Availability and Readiness Assessment.

measures for reducing the transmission of COVID-19. ${ }^{19} 20$ Using the same data as above, we also assessed hand hygiene practices, access to water and the availability of handwashing stations in a household.

Previous studies have shown that underlying chronic comorbidities and behavioural factors such as cigarette, alcohol and khat consumption were associated with more severe COVID-19 infections. ${ }^{21}{ }^{22}$ Data on khat chewing and the alcohol consumption rate were obtained from the EDHS $2016,{ }^{12}$ and data on cigarette smoking were obtained from the Ethiopia Public Health Institute Stepwise approach to Surveillance (STEPS) study. ${ }^{23}$ The STEP survey was also used to measure the prevalence of selected non-communicable diseases (NCDs) such as hypertension, heart disease and diabetes mellitus (DM).

The level of preparedness and readiness of health facilities to detect, manage and control the COVID-19 pandemic at a given location was measured using data from the Service Availability and Readiness Assessment (SARA) survey. ${ }^{24}$ For each geolocation, the obtained measures include the availability and readiness of facilities in terms of basic amenities and equipment, standard precautions, diagnostic capacities and essential medicines. In addition, data on service readiness for specific diseases such as DM, chronic respiratory disease (CRD) and tuberculosis (TB), as well as the availability of intensive care units (ICUs) and laboratory facilities, were obtained from this same survey. To augment the health facility data, we extracted population-level indicators on healthcare access and barriers to care from EDHS 2016. ${ }^{12}$

Finally, climatic data (temperature, precipitation, humidity and sunlight exposure) were obtained from the WorldClim V.2.0 Global Climate Database. ${ }^{25}$ These data were extracted at a spatial resolution of $30 \mathrm{~s}$ or $\sim 1 \mathrm{~km}^{2}$ and were considered indicators of COVID-19 infection in this study. 


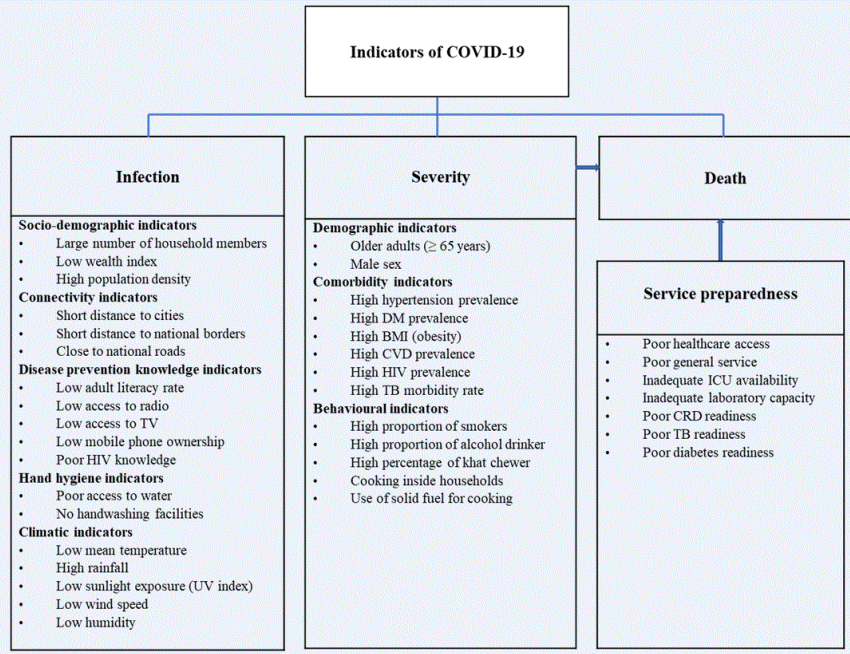

Figure 1 Indicators for the vulnerability of COVID-19 infection, severity, service, preparedness and related death. CVD, cardiovascular disease prevalence; DM, diabetes mellitus; ICU, intensive care unit; TB, tuberculosis.

\section{Geospatial data processing}

All data were georeferenced using a geographical information system, ArcGIS V.10.6.1 software (ESRI, Redlands, California, USA). The ideal resolution for spatial analysis was a latitude and longitude point that represented the location of the data cluster (point-level data), but when these were not available, we geolocated the available data to the smallest geographical areal unit, typically representing an administrative unit such as village or districts. In instances when the latitude and longitude coordinates of the village or district were not available in the dataset, centroids of the village or districts were also identified using Google Maps. A very small rectangular polygon (fishnet) with its centroid (fishnet centroid) covering the whole territory of Ethiopia was created using a sampling tool under the data management tools in the ArcToolbox (figure 2). The fishnet centroid contained a unique identification number and was used as a common georeferenced system to process, join and extract the raster and vector data collected from various sources. All vector data (point, polygon and line) were converted to raster data using geostatistical methods. ${ }^{26}$ Raster grids were then resampled to the common georeferenced system at a spatial resolution of $1 \mathrm{~km} \times 1 \mathrm{~km}$. Finally, a raster mask covering the entire country was created by clipping smaller spatial units from a large global raster data source.

\section{Statistical analyses}

Geostatistical techniques such as spatial autocorrelation, kriging and semivariograms were applied to create a prediction grid surface from a scattered set of points. ${ }^{27}$ Kriging assumes that the distance or direction between sample points reflects a spatial correlation that can be used to explain variation in the surface. ${ }^{28}$ Since the variables had different units of measurement, the datasets were normalised using a min-max approach to a standard scale ranging from 0 (the lowest risk) to 100 (the highest risk). ${ }^{29}$ After normalisation, the indicators were averaged to create a vulnerability index, measuring the risk of COVID-19 for each geolocation. ${ }^{30}$ The vulnerability indices were calculated separately for each domain, namely, the vulnerability to infection, case severity and likelihood of death from COVID-19. The three domains were then averaged to produce the overall COVID-19 vulnerability index. Given that COVID-19 is a new virus, there is a lack of evidence for assigning weights for each indicator. Hence, equal weight was given to all indicators when calculating the arithmetic mean for the vulnerability indices. However, we also used principal component analysis (PCA) and geometric mean methods, which produced broadly similar results (online supplemental figures 2 and 3). The risk maps were then created separately for infection, case severity, service preparedness and death from the composite index using geostatistical tools in ArcGIS. All data transformations were performed in $\mathrm{R}^{31}$ All items included in this study are available in the STROBE (Strengthening the Reporting of Observational Studies in Epidemiology) Statement checklist (online supplemental table 1).

\section{RESULTS}

\section{Vulnerability to COVID-19 infection}

Figure 3 shows the vulnerability map of COVID-19 infection in Ethiopia. The map highlights that most parts of the country are likely to have a relatively high vulnerability and be at substantial risk for COVID-19 infection. Most parts of the country are identified as vulnerable to COVID-19 infection, with the exception of Addis Ababa and the north-western Somali region. The peripheral areas of the country bordering Djibouti, Somalia, Eritrea and South Sudan appeared to be vulnerable to COVID-19 infection. These outlying areas are characterised by a low level of geographical connectivity and low scores for disease knowledge, hand hygiene and socioeconomic indices (online supplemental figure 4). They also have certain climatic factors that were found to be important indicators of COVID-19 transmission.

\section{Vulnerability to severe cases of COVID-19 infection}

Areas across the Amhara region and most parts of the Oromia region are likely to experience severe forms of COVID-19 that require hospitalisation and ICU admission. Some parts of the SNNPR are also expected to be at high risk of severe COVID-19 infections. The combination of demographic (high proportion of older adults), comorbidity (high prevalence of hypertension, DM, obesity, HIV and TB), and behavioural and economic indicators (high proportion of smokers and high level of alcohol and khat consumption, interior cooking and solid fuel use) renders these parts of the country at a higher risk of severe forms of COVID-19. Figure 4 shows the levels of vulnerability to severe forms of COVID-19.

\section{Vulnerability to death from COVID-19}

People living around border areas in Ethiopia are at a high risk for COVID-19-related death, as illustrated in figure 5. Districts and zones in the Benishangul-Gumuz, Gambela, Afar, SNNPR, Dire Dawa, Southwest Somali, Northwest 
Table 2 Evidence for risk of COVID-19 infection, severity and death

\begin{tabular}{|c|c|c|c|}
\hline Indicators & $\begin{array}{l}\text { Risk } \\
\text { factors }\end{array}$ & Evidence & References \\
\hline \multicolumn{4}{|l|}{ Demographic indicators } \\
\hline Male sex & Severity & $\begin{array}{l}\text { Death from and severity of COVID-19 was strongly associated with being male } \\
\text { (HR } 1.99,95 \% \mathrm{Cl} 1.88 \text { to } 2.10)\end{array}$ & Williamson et $a l^{40}$ \\
\hline Older age & Severity & $\begin{array}{l}\text { Older than } 65 \text { years were risk factors for disease progression in patients with } \\
\text { COVID-19 (OR=6.06, } 95 \% \mathrm{Cl} 3.98 \text { to } 9.22)\end{array}$ & Zheng et $a l^{22}$ \\
\hline \multicolumn{4}{|l|}{ Socioeconomic indicators } \\
\hline Population density & Infection & High population density is a risk factor for COVID-19 infection & Ahmadi et al ${ }^{41}$ \\
\hline $\begin{array}{l}\text { Number of household } \\
\text { members }\end{array}$ & Infection & $\begin{array}{l}\text { Areas with a higher percentage of households with more than one person per } \\
\text { room had a higher incidence of COVID- } 19\end{array}$ & Ahmad et $a l^{42}$ \\
\hline Low wealth index & Infection & $\begin{array}{l}\text { Socioeconomic deprivation (RR } 1.26 \text { per SD increase in Townsend Index) } \\
\text { associated with COVID-19 infection }\end{array}$ & Ho et $a{ }^{43}$ \\
\hline \multicolumn{4}{|l|}{ Connectivity indicators } \\
\hline Travel times to cities & Infection & $\begin{array}{l}\text { The distance between Wuhan and other cities was inversely associated with the } \\
\text { numbers of COVID-19 cases in that city }\end{array}$ & Zheng et $a l^{44}$ \\
\hline $\begin{array}{l}\text { Proximity to national } \\
\text { borders }\end{array}$ & Infection & $\begin{array}{l}\text { Cross-country moment is a risk factor for COVID-19 transmission and } \\
\text { importation }\end{array}$ & Chinazzi et al ${ }^{45}$ \\
\hline Distance to major roads & Infection & $\begin{array}{l}\text { Spread of COVID-19 was correlated positively with public transportation per } \\
\text { capita }\end{array}$ & Ayenew et $a l^{16}$. \\
\hline \multicolumn{4}{|l|}{ Climatic indicators } \\
\hline Mean temperature & Infection & Low ambient temperatures are associated with more rapid spread of COVID-19 & Holtmann et al ${ }^{46}$ \\
\hline Mean precipitation & Infection & $\begin{array}{l}\text { Countries with higher rainfall measurements showed an increase in COVID-19 } \\
\text { transmission }\end{array}$ & Sobral et $a l^{47}$ \\
\hline Wind speed & Infection & $\begin{array}{l}\text { Areas with low values of wind speed associated with a high rate of COVID-19 } \\
\text { infection }\end{array}$ & Ahmadi et $a l^{41}$ \\
\hline Solar radiation & Infection & $\begin{array}{l}\text { Areas with low values of solar radiation exposure associated with a high rate of } \\
\text { COVID-19 infection }\end{array}$ & Ahmadi et al ${ }^{41}$ \\
\hline Water vapour pressure & Infection & $\begin{array}{l}\text { High humidity reduces the transmission of COVID-19. Water vapour pressure } \\
\text { negatively correctly with COVID-19 infection. }\end{array}$ & Wang et $a l^{4849}$ \\
\hline \multicolumn{4}{|l|}{ Behavioural indicators } \\
\hline Khat chewing & Severity & $\begin{array}{l}\text { There is an association between khat chewing and chronic illness such as HIV } \\
\text { infection, elevated diastolic blood pressure }\end{array}$ & Basker $^{50}$ \\
\hline Alcohol drinking & Severity & Patients with alcohol use disorders at increased risk for COVID-19 & Testino $^{21}$ \\
\hline Cigarette smoking & Severity & $\begin{array}{l}\text { Current smoking was a risk factor for disease progression in patients with } \\
\text { COVID-19 (OR=2.51, } 95 \% \mathrm{Cl} 1.39 \text { to } 3.32)\end{array}$ & Zheng et $a l^{22}$ \\
\hline $\begin{array}{l}\text { Cooking inside the } \\
\text { household }\end{array}$ & Severity & $\begin{array}{l}\text { Areas with a higher percentage of incomplete kitchen facilities had a higher } \\
\text { incidence of, and mortality associated with, COVID-19 }\end{array}$ & Ahmad et al ${ }^{42}$ \\
\hline Use solid fuel for cooking & Severity & $\begin{array}{l}\text { Areas with a higher percentage of incomplete kitchen facilities had a higher } \\
\text { incidence of, and mortality associated with, COVID-19 }\end{array}$ & Ahmad et $a l^{42}$ \\
\hline \multicolumn{4}{|c|}{ Disease prevention knowledge indicators } \\
\hline Adult illiteracy rate & Infection & Adult learning education is a tool to contain the COVID-19 pandemics & Lopes et $a l^{51}$ \\
\hline Access to listen to radio & Infection & Access to media is a crucial factor in public health responses to an outbreak & $\begin{array}{l}\text { Ayedee and } \\
\text { Manocha }^{52}\end{array}$ \\
\hline Access to watch TV & Infection & $\begin{array}{l}\text { Media (Television) has a significant role in creating a positive atmosphere in } \\
\text { COVID-19 }\end{array}$ & $\begin{array}{l}\text { Ayedee and } \\
\text { Manocha }^{52}\end{array}$ \\
\hline Mobile phone ownership & Infection & $\begin{array}{l}\text { Mobile phone calls and text messages help for the diagnosis, management and } \\
\text { control of infectious diseases }\end{array}$ & Wood et $\left.a\right|^{53}$ \\
\hline Knowledge towards HIV & Infection & $\begin{array}{l}\text { Knowledge towards an infectious disease such as HIV can help to control the } \\
\text { transmission of the diseases }\end{array}$ & Bertozzi et $\left.a\right|^{54}$ \\
\hline \multicolumn{4}{|l|}{ Hand hygiene indicators } \\
\hline Travel time to water sources & Infection & Adequate water supply is essential for the control of COVID-19 infection & $\mathrm{WHO}^{55}$ \\
\hline Place for handwashing & Infection & Hand washing is recommended by WHO for the control of COVID-19 infection & $\mathrm{WHO}^{56}$ \\
\hline
\end{tabular}


Table 2 Continued

\begin{tabular}{|c|c|c|c|}
\hline Indicators & $\begin{array}{l}\text { Risk } \\
\text { factors }\end{array}$ & Evidence & References \\
\hline $\begin{array}{l}\text { Soap or detergent } \\
\text { availability for handwashing }\end{array}$ & Infection & $\begin{array}{l}\text { Availability of soap or detergent is essential to keep hand hygiene for the } \\
\text { prevention of COVID-19 infection }\end{array}$ & $\mathrm{WHO}^{56}$ \\
\hline \multicolumn{4}{|l|}{ Comorbidity indicators } \\
\hline HTN & Severity & $\begin{array}{l}\text { Hypertension was statistically significant with a higher rate of servery and death } \\
(\mathrm{OR}=2.72,95 \% \mathrm{Cl} 1.60 \text { to } 4.64)\end{array}$ & Zheng et $\mathrm{al}^{22}$ \\
\hline BMI & Severity & $\begin{array}{l}\text { Death from COVID-19 was associated with higher BMI (HR } 1.27,95 \% \mathrm{Cl} 1.18 \text { to } \\
\text { 1.36) }\end{array}$ & Williamson et al ${ }^{40}$ \\
\hline CVD & Severity & $\begin{array}{l}\text { Cardiovascular disease was significantly associated with higher COVID-19 } \\
\text { servility and death (OR=5.19, } 95 \% \mathrm{Cl} 3.25 \text { to } 8.29)\end{array}$ & Zheng et $\left.a\right|^{22}$ \\
\hline HIV prevalence & Severity & $\begin{array}{l}\text { Mortality from COVID-19 was associated with immunosuppression (HR } 1.69 \text {, } \\
95 \% \mathrm{Cl} 1.21 \text { to } 1.34 \text { ) }\end{array}$ & Williamson et $a /^{40}$ \\
\hline \multicolumn{4}{|c|}{ Service availability and readiness indicators } \\
\hline Healthcare access problem & Death & Healthcare resource availability is associated with COVID-19 mortality & Ji et $a l^{6}$ \\
\hline General service readiness & Death & $\begin{array}{l}\text { General health service preparedness is essential for combating the COVID-19 } \\
\text { pandemic }\end{array}$ & $\mathrm{WHO}^{57}$ \\
\hline ICU availability & Death & Lack of critical care unite increase the risk of death from COVID-19 & Murthy et $\left.a\right|^{58}$ \\
\hline CRD readiness & Death & Cardiorespiratory disease (CRD) is a risk factor for COVID-19-related death & Zheng et $a l^{22}$ \\
\hline TB readiness & Death & TB determinants outcomes of patients with COVID-19 & Tadolini et $a^{59}$ \\
\hline Diabetes readiness & Death & Diabetes affects the prognosis of patients with COVID-19 & Zheng et $\mathrm{al}^{22}$ \\
\hline
\end{tabular}

. EDHS, Ethiopia Demographic and Health Survey; EMOH, Ethiopia Ministry of Health; EPHI, Ethiopia Public Health Institute; G-Econ, Geographically based Economic data; ICU, intensive care unit; MAP: SRTM, Malaria Atlas Project; Shuttle Radar Topography Mission; UN OCHA, United Nation Office for Coordination of Humanitarian Affairs; SARA, Service Availability and Readiness Assessment.

Amhara, Western Tigray, and Western and Eastern Oromia regions are at high risk for COVID-19-related death. The level of service preparedness and readiness to mitigate the health effects of COVID-19 appears to be very low in these regions (figure 6). Ethiopia's border regions have inadequate ICU availability and laboratory capacity as well as limited healthcare access. They also have low general and service-specific readiness, as shown in figure 6 .

\section{DISCUSSION}

This is the first study that maps vulnerability to COVID-19 infection, severe cases and associated death in Ethiopia at a high resolution. This is also the first study that has attempted to present the degree of service preparedness for COVID-19 across the country.

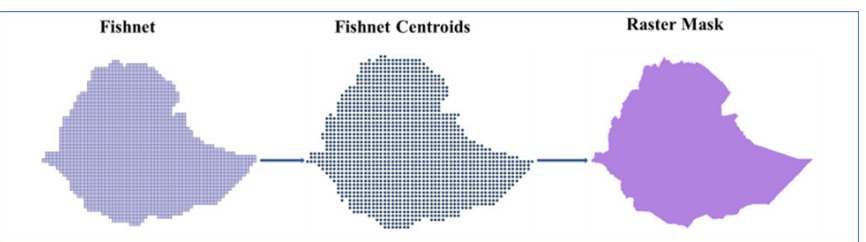

Figure 2 Rectangular polygon (fishnet), fishnet centroids and raster mask covering the whole territory of Ethiopia.
We found that most parts of the country are vulnerable to COVID-19 infections, and the greatest burden might be outside of Addis Ababa. It is likely that compared with other regions, a higher proportion of people from the Amhara and Oromia regions, the two most populous regions of the

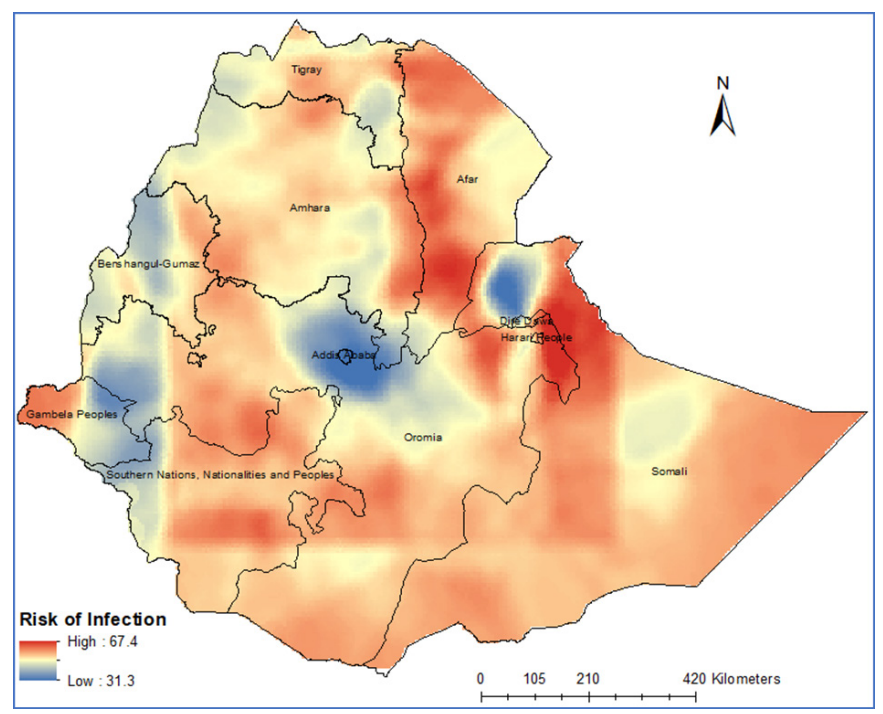

Figure 3 Vulnerability map to COVID-19 infection in Ethiopia. 


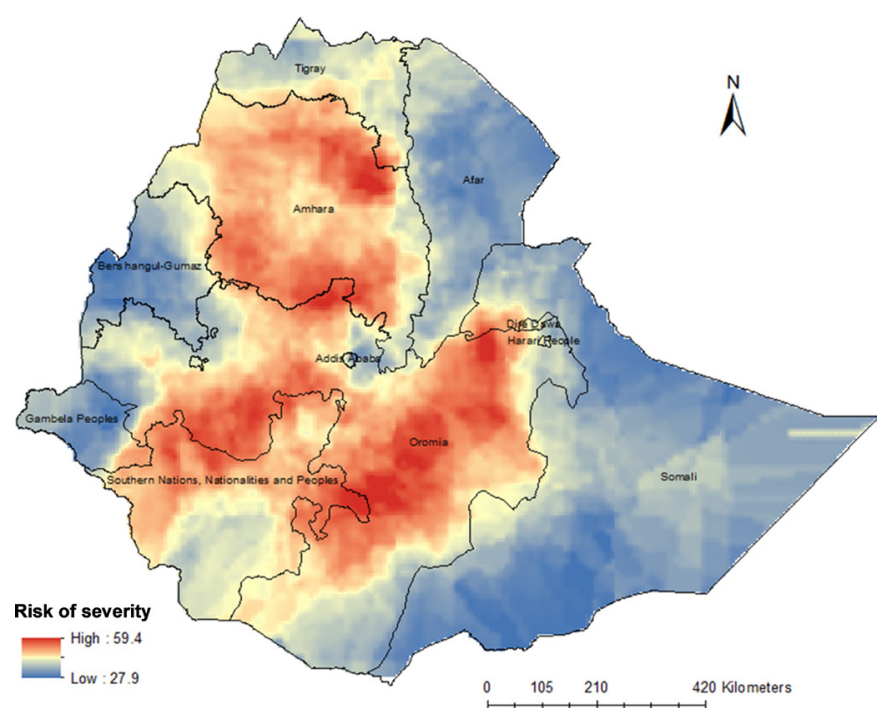

Figure 4 Vulnerability map to COVID-19 severity in Ethiopia.

country, will develop severe forms of COVID-19 leading to hospitalisation and ICU admission. Border areas of the country are also expected to face a higher risk of death than areas located in the central regions. The findings of this study are of paramount importance in preventing and controlling COVID-19 transmission and in designing targeted interventions, such as enacting travel restrictions, distributing preventative masks and determining which areas to prioritise if a COVID-19 vaccine becomes available. As some of these areas also have lower preparedness scores and low general and service-specific readiness scores, the findings have wider implications for allocating resources and strengthening the healthcare system after the COVID-19 pandemic.

Despite the disproportionately high infection rate in Addis Ababa at present (online supplemental figure 5), we found that the risk of COVID-19 infection is likely to become rather high in other regions. The high infection rate in Addis Ababa at this initial stage is expected, given that Addis Ababa is a

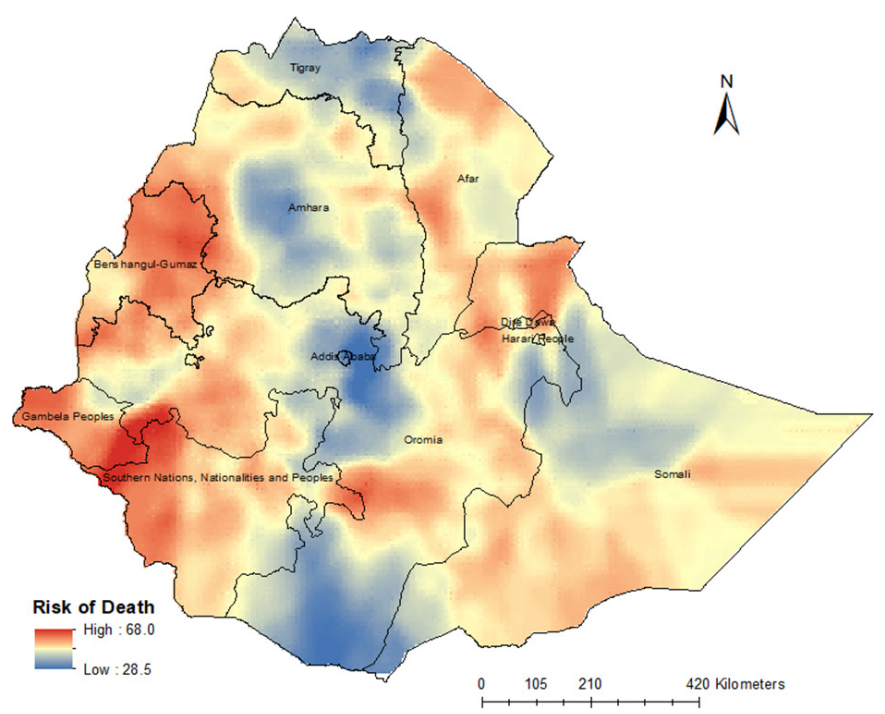

Figure 5 Vulnerability map to death from COVID-19 in Ethiopia.

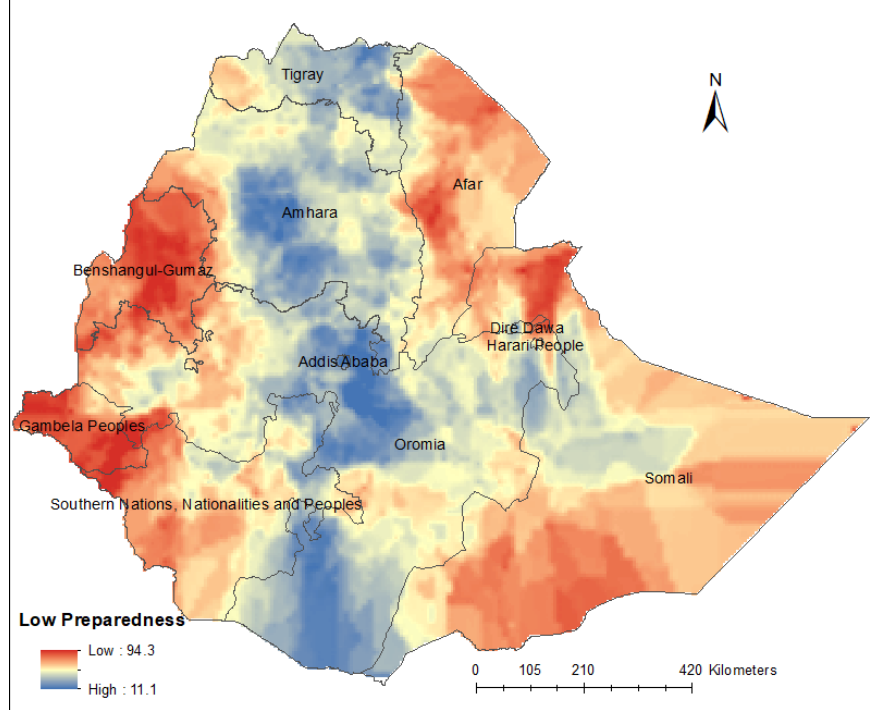

Figure 6 Vulnerability map to service preparedness for COVID-19 in Ethiopia.

major travel hub and Bole International Airport, located in the city, is one of the largest international airports in Africa. This exposes the city to a higher risk of imported cases and, subsequently, to an early surge of infections, leaving the areas outside the city at a higher risk of later infection. Second, we considered multifaceted risk factors (indicators) for COVID-19 infection in our geospatial model. This means that although the city has a high degree of connectivity, it is also characterised by higher scores for information penetration, knowledge of disease prevention and hand hygiene practices that could help slow the rate of infection in the city. ${ }^{12}$ Third, Addis Ababa has relatively better and more consistent test-and-contact tracing practices than in other parts of the country, which means that the chance of new infections being detected in the city are much greater than in other parts of the country. ${ }^{5}$ Future efforts to expand testing and tracing practices in other areas of the county are likely to increase the extent of confirmed infections in those other areas. Recent studies have demonstrated that effective social distancing and contact tracing can significantly reduce the rate of infection. ${ }^{3233}$ These interventions should be strengthened and expanded to areas identified as high risk in this study.

Our study also showed that the risk for severe cases of COVID-19 infection is high in most parts of the Amhara and Oromia regions. This may be due to the high prevalence of NCDs, which are associated with severe cases of COVID-19. Previous studies have revealed that the burden of NCDs, such as DM and hypertension, is high in these two regions. ${ }^{23} 3435$

Our study also revealed that peripheral areas sharing international borders are likely to see a greater number of COVID-19-related deaths. The high risk of death along the border areas might be attributed to low preparedness in case management and weak healthcare systems. In contrast, although the Amhara and Oromia regions may have more severe cases, the preparedness indicators show that the regions are better equipped to cope with these anticipated 
severe cases. However, our study suggests that additional preparation and capacity strengthening are needed mainly in the following areas: emergency response systems, case detection and capacity to care for patients. It is also equally important that hospitals have adequate supplies, healthcare personnel and life-saving medical intervention resources. Despite encouraging efforts by the Ethiopian government and stakeholders to prepare the healthcare system for the pandemic, the existing healthcare services in the country may face unprecedented challenges and crises due to the surge of patients that will require hospitalisation and ICU services at the same time. This can, however, be eased by implementing public health and social measures at the individual, community and public authority levels to prevent infections and subsequent health, economic and social consequences. ${ }^{36}$ Studies have shown that implementing nonpharmaceutical interventions such as physical distancing, mask use and closure of schools, especially during the early stages of infection, can reduce transmission and subsequent potential public health and economic crises. ${ }^{37}$

Further, we found notable regional disparities in health system preparedness and readiness levels in the country. This is important because if the healthcare system is well equipped to prevent and mitigate the spread of the pandemic, then the mortality rate from the disease can be markedly reduced. ${ }^{38}$ However, we observed that Ethiopia's border regions (ie, Benishangul-Gumuz, Gambella, Afar and Somali) have low preparedness levels. Nevertheless, comparisons between the border regions and other regions of the country need to be treated with care because Ethiopia in general has very low doctor-to-resident (1 doctor per 10000 people) and hospital bed-to-population (3 hospital beds per 10000 people) ratios. ${ }^{39}$ Several long-term, medium-term and short-term strategies can be implemented to mitigate these problems: (1) providing short-term training for potential actors such as community leaders, students, and traditional and modern medical practitioners; (2) recruiting additional staff to work in COVID-19-related healthcare; (3) establishing COVID-19 clinics and changing outpatient rooms to emergency clinics; (4) collaborating with private hospitals ahead of surges so that they can be used in the case such surges occur; and (5) establishing mobile clinics and temporary admission rooms in highly vulnerable areas.

\section{Strength and limitations}

This study has several strengths. First, the current study was conducted at a spatial resolution of $1 \mathrm{~km} \times 1 \mathrm{~km}$ across the entire territory of Ethiopia. Second, it incorporated a wide range of indicators from multiple sources. Third, it applied rigorous geospatial techniques, including spatial autocorrelation, kriging and semivariograms, to provide the best possible prediction maps. Finally, we produced vulnerability mapping for infection or transmission, case severity and associated death separately to assist with policy interventions related to each risk.

However, it is important to note some potential limitations of the study when interpreting the findings. First, the results need constant updating, as some of the variables used in the study may change overtime. Second, the data used in this study were not collected in the same year and the results might be changed if recently available data were used in the analysis. However, many of the variables used in this study were static and may not change over time. Moreover, we used the most recently available data for non-static variables such as EDHS data. Third, ongoing political turmoil in the country means that the dynamics of transmission may change depending on the location and severity of these incidents. For example, in areas of low security resulting from active conflict, the local health systems might be ill-prepared to prevent and control COVID-19. Insecurity also may generate unpredictable population movements, and this in turn could exacerbate infection dynamics in the country. Fourth, the calculation of the composite risk factor index was based on an unweighted average under the assumption that all indicators have equal importance, which may or may not be the case. Some of the variables included in our score may have greater effects on vulnerability to infection, case severity and likelihood of death than others. Giving equal weight for all these variables may influence the findings of our study, but the exact effect is hard to tell. However, we have calculated a weighted index using PCA as an alternative method, which produced broadly similar results (online supplemental figures 2 and 3). Lastly, some important indicators, such as psychosocial and clinical factors (eg, mental illness, quality of life and social support), were not captured in our modelling due to the lack of geocoded data.

\section{CONCLUSIONS}

Although nearly three-quarters of the current COVID-19 cases reported in Ethiopia are concentrated in and around Addis Ababa, this study predicts that over time, the risk of COVID-19 infection will be higher across most other parts of the country. A higher proportion of people from the Amhara region, most of the Oromia region and some parts of the SNNPR will develop severe cases of infection. Additionally, the risk of death will be higher in the regions of the country with low preparedness scores for COVID-19 response. Hence, the preventative and control measures that are currently in place in the capital city should be strengthened and extended to regional areas, especially to high-risk areas, to prevent and mitigate the risk of COVID-19 infection, lower the number of severe cases and limit the number of associated deaths in Ethiopia.

\section{Author affiliations}

${ }^{1}$ Wesfarmers Centre of Vaccines and Infectious Diseases, Telethon Kids Institute, Nedlands, Western Australia, Australia

${ }^{2}$ School of Population Health, Curtin University, Perth, Western Australia, Australia ${ }^{3}$ Department of Epidemiology and Biostatistics, Institute of Public Health, University of Gondar, Gondar, Ethiopia

${ }^{4}$ School of Women's and Children's Health, University of New South Wales, Sydney, New South Wales, Australia

${ }^{5}$ Burnet Institute, Melbourne, Victoria, Australia

${ }^{6}$ Department of Medicine at Royal Melbourne Hospital and Centre for Epidemiology and Biostatistics, Melbourne School of Population and Global Health, The University of Melbourne, Melbourne, VIC, Australia 
${ }^{7}$ College of Medicine and Public Health, Flinders University, Adelaide, South Australia, Australia

${ }^{8}$ School of Public Health, Mekelle University, Mekelle, Ethiopia

${ }^{9}$ Department of Medicine, School of Clinical Sciences at Monash Health, Monash University, Melbourne, VIC, Australia

${ }^{10}$ St Paul's Hospital Millennium Medical College, Addis Ababa, Ethiopia

${ }^{11}$ Telethon Kids Institute, The University of Western Australia, Nedlands, Western Australia, Australia

${ }^{12}$ Western Sydney University, Penrith South, New South Wales, Australia

${ }^{13}$ Monitoring Evaluation and Research, Amref Health Africa in Ethiopia, Addis Ababa, Ethiopia

${ }^{14}$ University of Canberra, Canberra, Australian Capital Territory, Australia

${ }^{15}$ School of Pharmacy, Mekelle University, Mekelle, Ethiopia

${ }^{16}$ Monash University, Clayton, Victoria, Australia

${ }^{17}$ School of Nursing, Mekelle University, Mekelle, Ethiopia

${ }^{18}$ School of Pharmacy, University of Gondar, Gondar, Ethiopia

${ }^{19}$ University of New England, Armidale, New South Wales, Australia

${ }^{20}$ University of Tasmania Faculty of Health, Hobart, Tasmania, Australia

${ }^{21}$ Queensland University of Technology, Brisbane, Queensland, Australia

${ }^{22}$ Lifelong Health, South Australia Health and Medical Research Institute, Adelaide,

South Australia, Australia

${ }^{23}$ School of Pharmacy and Medical Sciences, Therapeutics Research Centre,

University of South Australia, Adelaide, South Australia, Australia

${ }^{24}$ Haramaya University, Dire Dawa, Ethiopia

${ }^{25}$ Faculty of Health and Medicine, The University of Newcastle, Callaghan, New

South Wales, Australia

${ }^{26}$ Australian Rivers Institute, Griffith University, Nathan, Queensland, Australia

${ }^{27}$ College of Health Science, Debre Markos University, Debre Markos, Ethiopia

${ }^{28}$ University of Technology Sydney, Sydney, New South Wales, Australia

${ }^{29}$ Deakin University, Burwood, Victoria, Australia

${ }^{30}$ School of Pharmacy, The University of Sydney, Sydney, New South Wales, Australia

${ }^{31}$ Ethiopian Public Health Institute, Addis Ababa, Ethiopia

${ }^{32}$ Institute for Health Metrics and Evaluation, University of Washington, Seattle,

Washington, USA

${ }^{33}$ Vaccinology and Immunology Research Trials Unit, Women's and Children's

Hospital, Adelaide, South Australia, Australia

${ }^{34}$ Robinson Research Institute, Adelaide Medical School, University of Adelaide, Adelaide, Australia

${ }^{35}$ Clinical Pharmacy Department, School of Pharmacy, University of Gondar, Gondar, Ethiopia

${ }^{36}$ The George Institute for Global Health, University of New South Wales, Sydney,

New South Wales, Australia

${ }^{37}$ Deakin University, Geelong, Institute for Health Transformation, Melbourne,

Victoria, Australia

${ }^{38}$ College of Medicine, Qatar University, Doha, Qatar

Twitter Hailay Gesesew @Gesesew, Azeb Gebresilassie Tesema @Azebdej and Fisaha Haile Tesfay @FisahaHaile

Contributors KAA, YAG, YK, DMF, DNK, YAM, HG, MMB, MDM, AAAd, and BAD conceptualised the study. KAA designed and run the geospatial analysis. YAG involved in the data analysis. KAA, YAM, DMF, DNK, and YAG drafted the manuscript HG, MMB, AAAd, MDM, BAD, SA, AA, AAAy, WMB, KTG, TG, ATG, LG, ABG, HTK, GDK, CTL, LBM, AHM, HM, HGT, AGT, FHT, BLW, and YK Critically reviewed and revised the drafted manuscript. KAA, YK, and AHM were responsible for quality control of accuracy and integrity of data. All the authors interpreted the data. All authors contributed to the final draft and finally approved it to be published. All authors agreed to be accountable for all aspects of the work for any issue related to the accuracy or integrity of any part of the work. The corresponding author attests that all listed authors meet authorship criteria and that no others meeting the criteria have been omitted.

Funding The authors have not declared a specific grant for this research from any funding agency in the public, commercial or not-for-profit sectors.

Map disclaimer The depiction of boundaries on this map does not imply the expression of any opinion whatsoever on the part of BMJ (or any member of its group) concerning the legal status of any country, territory, jurisdiction or area or of its authorities. This map is provided without any warranty of any kind, either express or implied.

Competing interests None declared.
Patient consent for publication Not required.

Provenance and peer review Not commissioned; externally peer reviewed.

Data availability statement All data relevant to the study are included in the article or uploaded as supplementary information. Extra data is available by emailing the corresponding author (KAA): kefyalew.alene@curtin.edu.au.

Supplemental material This content has been supplied by the author(s). It has not been vetted by BMJ Publishing Group Limited (BMJ) and may not have been peer-reviewed. Any opinions or recommendations discussed are solely those of the author(s) and are not endorsed by BMJ. BMJ disclaims all liability and responsibility arising from any reliance placed on the content. Where the content includes any translated material, BMJ does not warrant the accuracy and reliability of the translations (including but not limited to local regulations, clinical guidelines, terminology, drug names and drug dosages), and is not responsible for any error and/or omissions arising from translation and adaptation or otherwise.

Open access This is an open access article distributed in accordance with the Creative Commons Attribution Non Commercial (CC BY-NC 4.0) license, which permits others to distribute, remix, adapt, build upon this work non-commercially, and license their derivative works on different terms, provided the original work is properly cited, appropriate credit is given, any changes made indicated, and the use is non-commercial. See: http://creativecommons.org/licenses/by-nc/4.0/.

\section{ORCID iDs}

Yohannes Adama Melaku http://orcid.org/0000-0002-3051-7313

Hailay Gesesew http://orcid.org/0000-0002-3531-4400

Akilew Awoke Adane http://orcid.org/0000-0002-3022-5230

Berihun Assefa Dachew http://orcid.org/0000-0002-4041-6129

Woldesellassie M Bezabhe http://orcid.org/0000-0002-3028-6949

Henok Getachew Tegegn http://orcid.org/0000-0003-0644-0958

Fisaha Haile Tesfay http://orcid.org/0000-0003-0399-1711

Yohannes Kinfu http://orcid.org/0000-0001-9607-6891

\section{REFERENCES}

1 Yang P, Wang X. COVID-19: a new challenge for human beings. Cell Mol Immunol 2020;17:555-7.

2 Cucinotta D, Vanelli M. WHO declares COVID-19 a pandemic. Acta Biomed 2020;91:157-60.

3 WHO. Coronavirus disease (COVID-19): situation report, 2020.

4 Gilbert M, Pullano G, Pinotti F, et al. Preparedness and vulnerability of African countries against importations of COVID-19: a modelling study. Lancet 2020;395:871-7.

5 Baye K. COVID-19 prevention measures in Ethiopia: current realities and prospects. Intl Food Policy Res Inst 2020.

$6 \mathrm{Ji} \mathrm{Y,} \mathrm{Ma} \mathrm{Z,} \mathrm{Peppelenbosch} \mathrm{MP,} \mathrm{et} \mathrm{al.} \mathrm{Potential} \mathrm{association} \mathrm{between}$ COVID-19 mortality and health-care resource availability. Lancet Glob Health 2020;8:e480.

7 Mehra MR, Desai SS, Kuy S, et al. Cardiovascular disease, drug therapy, and mortality in COVID-19. New Eng J Med 2020.

8 ACSS. Mapping risk factors for the spread of COVID-19 in Africa: Africa center for strategic studies, 2020.

9 UN. Department of Economic and Social Affairs. Population division, 2019.

10 Workie NW, Ramana GN. The health extension program in Ethiopia, 2013.

11 Global Administrative Areas. GADM database of global administrative areas, 2012.

12 CSA. Ethiopia demographic and health survey 2016. Addis Ababa, Ethiopia, and Rockville, Maryland, USA, 2016.

13 Tatem AJ. WorldPop, open data for spatial demography. Sci Data 2017:4:1-4.

14 Weiss DJ, Nelson A, Gibson HS, et al. A global map of travel time to cities to assess inequalities in accessibility in 2015. Nature 2018:553:333-6.

15 ICF. The DHS program spatial data Repository, 2018.

16 Ayenew B, Yitayew M, Pandey D. Challenges and opportunities to tackle COVID-19 spread in Ethiopia. J Peer Sci 2020;2.

17 Bank W. Ethiopia roads, 2014.

18 Zhong B-L, Luo W, Li H-M, et al. Knowledge, attitudes, and practices towards COVID-19 among Chinese residents during the rapid rise period of the COVID-19 outbreak: a quick online cross-sectional survey. Int J Biol Sci 2020;16:1745-52.

19 Anderson RM, Heesterbeek H, Klinkenberg D, et al. How will countrybased mitigation measures influence the course of the COVID-19 epidemic? Lancet 2020;395:931-4. 
20 Xiao Y, Torok ME. Taking the right measures to control COVID-19. Lancet Infect Dis 2020;20:523-4.

21 Testino G. Are patients with alcohol use disorders at increased risk for Covid-19 infection? Alcohol Alcohol 2020;55:344-6.

22 Zheng Z, Peng F, Xu B, et al. Risk factors of critical \& mortal COVID-19 cases: A systematic literature review and meta-analysis. $J$ Infect 2020;81:e16-25.

23 EPHI. Ethiopia STEPS report on risk factors for chronic noncommunicable diseases and prevalence of selected NCDS. Addis Ababa, 2016.

$24 \mathrm{EPHI}$. Ethiopia service availability and readiness assessment (SARA) final report. Addis Ababa, 2018.

25 Fick SE, Hijmans RJ. WorldClim 2: new 1-km spatial resolution climate surfaces for global land areas. Int $\mathrm{J}$ Climatol 2017;37:4302-15.

26 Burrough PA. GIS and geostatistics: essential partners for spatial analysis. Environ Ecol Stat 2001;8:361-77.

27 Childs C. Interpolating surfaces in ArcGIS spatial analyst. ArcUser 2004;3235:32-5.

28 Negreiros J, Painho M, Aguilar F, et al. Geographical information systems principles of ordinary kriging interpolator. $J$ Appl Sci 2010;10:852-67.

29 Patro S, Sahu KK. Normalization: a preprocessing stage. arXiv preprint arXiv 2015;150306462.

30 Moore M, Gelfeld B, Okunogbe A, et al. Identifying future disease hot spots: infectious disease vulnerability index. Rand Corporation, 2016.

31 R Foundation for Statistical Computing. R: A language and environment for statistical computing [online]. Vienna, Austria: R Foundation for Statistical Computing, 2020.

32 Siraj A, Worku A, Berhane K, et al. Early estimates of COVID-19 infections in small, medium and large population clusters. BMJ Glob Health 2020;5:e003055.

33 Getaneh Y, Yizengaw A, Adane S. Global lessons and potential strategies in combating COVID-19 pandemic in Ethiopia: systematic review. medRxiv2020.

34 Tesfaye TD, Temesgen WA, Kasa AS, et al. Prevalence and associated factors of hypertension in Amhara regional state city and its' surrounding rural districts: a community-based cross-sectional study. Afr Health Sci 2019;19:2580-90.

35 Kibret KT, Mesfin YM. Prevalence of hypertension in Ethiopia: a systematic meta-analysis. Public Health Rev 2015;36:1-12.

36 Hartley DM, Perencevich EN. Public health interventions for COVID-19: emerging evidence and implications for an evolving public health crisis. JAMA 2020;323:1908-9.

37 Pan A, Liu L, Wang C, et al. Association of public health interventions with the epidemiology of the COVID-19 outbreak in Wuhan, China. JAMA 2020;323:1915-23.

38 Stafford N. Covid-19: why Germany's case fatality rate seems so low. BMJ 2020;369:m1395.

39 WHO. Density of physicians (total number per 1000 population. Global Health Observatory (GHO), 2017.

40 Williamson E, Walker AJ, Bhaskaran KJ. OpenSAFELY: factors associated with COVID-19-related hospital death in the linked electronic health records of 17 million adult NHS patients. medRxiv 2020.

41 Ahmadi M, Sharifi A, Dorosti S, et al. Investigation of effective climatology parameters on COVID-19 outbreak in Iran. Sci Total Environ 2020;729:138705.

42 Ahmad K, Erqou S, Shah N. Association of poor housing conditions with COVID-19 incidence and mortality across US counties. medRxiv2020.

43 FK H, Celis-Morales CA, Gray SR. Modifiable and non-modifiable risk factors for COVID-19: results from UK Biobank. medRxiv 2020

44 Zheng R, Xu Y, Wang W, et al. Spatial transmission of COVID-19 via public and private transportation in China. Travel Med Infect Dis 2020;34:101626.

45 Chinazzi M, Davis JT, Ajelli M, et al. The effect of travel restrictions on the spread of the 2019 novel coronavirus (COVID-19) outbreak. Science 2020;368:395-400.

46 Holtmann M, Jones M, Shah A, et al. Low ambient temperatures are associated with more rapid spread of COVID-19 in the early phase of the endemic. Environ Res 2020;186:109625.

47 Sobral MFF, Duarte GB, da Penha Sobral AIG, et al. Association between climate variables and global transmission oF SARS-CoV-2. Sci Total Environ 2020;729:138997.

48 Wang J, Tang K, Feng K, et al. High temperature and high humidity reduce the transmission of COVID-19. SSRN Journal 2020;188.

$49 \mathrm{Li}$ J, Zhang L, Ren Z. Meteorological factors correlate with transmission of 2019-nCoV: proof of incidence of novel coronavirus pneumonia in Hubei Province, China. medRxiv2020.

50 Basker GV. A review on hazards of khat chewing. Int J Pharm Pharm Sci 2013:5:74-7.

51 Lopes H, McKay V, de Cima P. Adult learning and education as a tool to contain pandemics: the COVID-19 experience. Int Rev Educ 2020;66:575-602.

52 Ayedee N, Manocha DS. Role of media (television) in creating a positive atmosphere in COVID-19 during Lockdown in India. SSRN Journal 2020.

53 Wood CS, Thomas MR, Budd J, et al. Taking connected mobilehealth diagnostics of infectious diseases to the field. Nature 2019;566:467-74.

54 Bertozzi S, Padian NS, Wegbreit J. HIV/AIDS prevention and treatment. Dis Cont Priorit Develop Country 2006;2:331-70.

55 WHO. Water, sanitation, hygiene, and waste management for the COVID-19 virus: interim guidance. World Health Organization, 2020.

$56 \mathrm{WHO}$. Infection prevention and control guidance for long-term care facilities in the context of COVID-19: interim guidance. World Health Organization, 2020.

57 WHO. Who releases guidelines to help countries maintain essential health Servics during the COVID-19 pandemic. Geneva, Switzerland: World Health Organization, 2020.

58 Murthy S, Gomersall CD, Fowler RA. Care for critically ill patients with COVID-19. JAMA 2020;323:1499-500.

59 Tadolini M, Codecasa LR, García-García J-M, et al. Active tuberculosis, sequelae and COVID-19 co-infection: first cohort of 49 cases. Eur Respir J 2020;56 doi:10.1183/13993003.01398-2020 